\title{
Ensuring safe operation of buildings and structures
}

\author{
Elena Gryaznova* \\ Moscow State University of Civil Engineering, Yaroslavskoe shosse, 26, Moscow, 129337, Russia
}

\begin{abstract}
It is possible to ensure safety of the entire construction process as well as safe operation of buildings and structures in future by timely implementation of geotechnical monitoring. Geotechnical monitoring of buildings and structures is a complex research of "soil base - foundation above ground structures of a building". Geotechnical monitoring studies behaviour of buildings and structures during construction and operation and, safety measures to prevent hazardous situations in future are undertaken upon analysis of acquired results. Geotechnical monitoring comprises combination of works, including field observation for structures' behaviour of a building under construction or renovation, its foundation, including soil body surrounding the structure under construction, and field observation for structures of surrounding buildings. Such monitoring allows us to timely detect and prevent non-reversible processes that occur in "soil base - foundation - above ground structures of a building" system. Considering task in hand to ensure safety and security of buildings and structures, list of geotechnical monitoring works can be divided into following blocks: object monitoring; hydrogeological monitoring; ecological monitoring and computational and analytical block which makes assessment of current geotechnical situation on the construction object and develops relevant recommendation for further continuation of works. This article looks into special aspects of multiyear (2005 - 2019) geotechnical monitoring for deformational behaviour of buildings under operation, open parking spaces No.1 and No.2, located in area of effect from construction of railway connecting Vnukovo-1 airport and Kievskiy train station in Moscow and in the area of effect of new Vnukovo-1 airport construction. Article looks into tasks to ensure regular operation of existing buildings and monitoring of hazardous situations and their origin caused by construction works or poor technical condition of monitored objects. Particular to renovation of Vnukovo-1 airport, that started in 2005 is the fact that during construction it was necessary to ensure operation of a number of maintained buildings. Among them are open parking spaces No.1 and No.2.
\end{abstract}

* Corresponding author: GryaznovaEM@mgsu.ru 


\section{Main part}

Many years of construction experience demonstrated a role of geotechnical monitoring in ensuring of safe and reliable functioning of buildings and structures, both during their construction (renovation) and during their further operation. Geotechnical consists of carrying out a complex of works, including field observations of structures' behaviour in newly constructed or reconstructed structure, its foundation, including the soil body surrounding structure under construction, as well as monitoring structures of surrounding buildings. Implementation of such monitoring allows to timely detect and prevent irreversible processes that occur in "soil base - foundation - above ground structures of a building" system. Considering task in hand to ensure safety and security of buildings and structures, list of geotechnical monitoring works can be divided into following blocks: object monitoring, which includes visual and instrumental works, that allow to asses current technical state of main load-bearing structures, located in the area affected by the new construction (renovation); hydrological monitoring, determining possible changes in groundwater levels during construction works; geomechanical monitoring which provides assessment of possible changes of physical and mechanical properties of soil base located in the area affected by the new construction (renovation); ecological monitoring, which allows to manage ecological situation on construction site, and computational and analytical block which makes assessment of current geotechnical situation on the construction object and develops relevant recommendation for further continuation of works.

In this article, lets focus on the special aspects of multiyear (2005 - 2019) geotechnical monitoring for deformational behaviour of buildings under operation, open parking spaces No.1 and No.2, located in area close to the railway station, and in the area of effect from construction of railway connecting Vnukovo-1 airport and Kievsky train station in Moscow and new Vnukovo-1 airport.

Particular to renovation of Vnukovo-1 airport, that started in 2005 is the fact that during construction it was necessary to ensure operation of a number of maintained buildings. Among them are open parking spaces No.1 and No.2. (Fig.1,2)

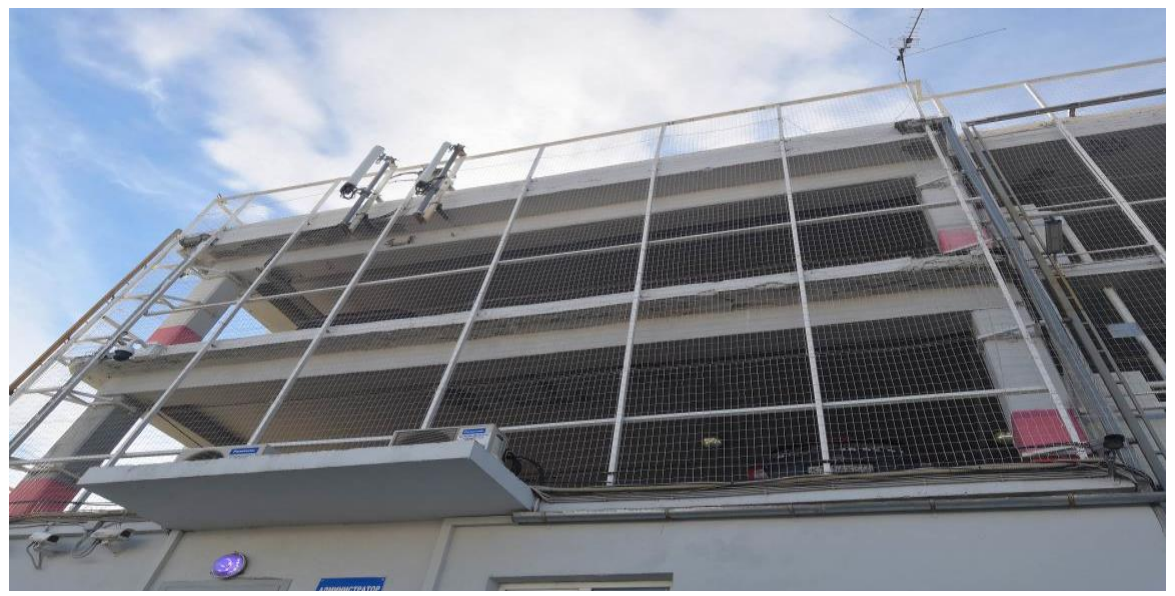

Fig. 1. Fragment of the parking No.1 facade 


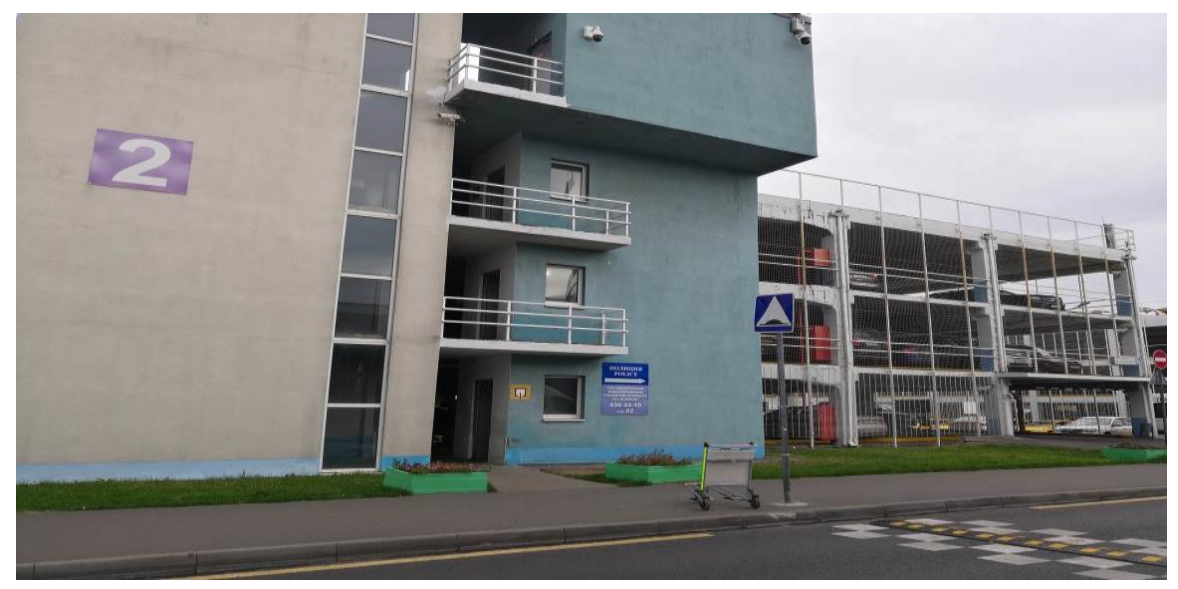

Fig. 2. Fragment of the parking No.2 facade

Open parking No.1 and No.2 are three-tiered buildings, built in 2004, designed by ZAO "Masterskaya arkhitektora V.M. Ginzburga" with design changes by ZAO "Proektstroynauka". Their dimensions are $80,4 \times 40,8 \mathrm{~m}$ and height $\mathrm{H}=13,5 \mathrm{~m}$. Building criticality level - regular. Structural diagram of a building - skeletonized. Foundation under columns is pedestal footing made from monolithic reinforced concrete. Laying depth of the foundation is $2.9 \mathrm{~m}$, footing dimensions are $2.4 \times 2.4 \mathrm{~m}$ by outer axles and $2.4 \times 3.0 \mathrm{~m}$ by middle axles.

Reinforced concrete columns with $40 \times 40 \mathrm{~cm}$ section. Column grid $6 \div 7,2 \mathrm{~m} \times 5,1 \div 7,2 \mathrm{~m}$.

Floor slabs - braced, monolithic, made as a slab with $20 \mathrm{~cm}$ thickness on beams with $40 \div 30$ cm section.

Covering structures made similarly to interflooring slabs.

Before the construction of the railway line connecting Vnukovo-1 airport and Kievsky railway station in Moscow and buildings of the new Vnukovo-1 airport, MGSU in 2005 carried out a survey of the building structures of parking No.2, located in the area affected by tunnel construction, with aim to determine the category of its technical condition. According to the survey of the building, numerous cracks with a width of $0.1-0.5 \mathrm{~mm}$ were detected in the slabs and floor beams. It was also noted that the floor slabs under a load of $500-1000 \mathrm{~kg} / \mathrm{m} 2$ in the spans are overloaded and their load-bearing capacity is not enough to support existing loads. The geodetic levelling carried out by MGSU showed that parking No.2 building underwent a subsidence of up to $28 \mathrm{~mm}$, and uneven subsidence of the foundations were 0.00242 and exceeded the maximum permissible values $(0.002)$, according to the SNiP 2.02.01-83* valid at that time [1]. The technical condition of the load-bearing structures of the parking building was assessed as satisfactory. In this regard, the maximum permissible value of additional vertical deformations at the first stage of geodetic monitoring was set to $30 \mathrm{~mm}$, and the relative difference in subsidence -0.001 . From April 2005 to the end of the year, for the period of the railway station tunnel construction, MGSU organized geodetic monitoring of the deformational behaviour of the building and monitoring crack formation, which resulted in additional building subsidence of about $10 \mathrm{~mm}$, and the relative difference of the subsidence was 0.0042 . Monitoring was interrupted after completion of the railway line construction behind the parking building. Experience gained during tunnelling showed the consequences for neglecting prognosis of impact caused by the new construction on existing buildings and pointed to the mistakes on protection of buildings from the impact of construction works, related to tunnelling. Those mistakes were considered during construction of the foundation pit for the new airport terminal. 
At this stage, calculations to assess the impact of the terminal construction on the surrounding buildings were carried out by MGSU employees. According to the results of calculations, it has been established that among other buildings parking No. 2 was again in the area affected by the new construction.

Because of that, MGSU employees in 2006 designed strengthening of reinforced concrete structures of parking No.2 with steel structures. In addition, it was advised prior to the implementation of measures to strengthen parking structures, to limit the linear load on the floor slabs.

During construction of the new air terminal (2006), MGSU continued monitoring of vertical deformations and crack formation of the parking No.2 building. At this stage of monitoring, maximum allowable value of the subsidence was set to $2 \mathrm{~mm}$, and the relative difference between the sediment was set to 0.001 .

The last cycle of observations was carried out by MGSU in May 2007, according to the results of which, the total deformations during 2006-2007 lay in the range from $-0.6 \mathrm{~mm}$ to $+3.6 \mathrm{~mm}$.

At the same time, MGSU employees conducted a visual inspection of the parking No.2 structures, during which it was found that for the period from 12.2006. till 05.2007, the number of defects increased to $20 \%$. The technical condition category of the structures, in accordance with SP 13-102-2003 [2], for that period, was assessed as being only partially operational.

Another assessment of the supporting structures technical condition of multi-tier parking building No.1 and No.2 was carried out by MGSU in 2009.

According to the results of this survey, excess unevenness of the skeleton subsidence and excess deflection of the floor slabs were found. The main damage identified during the survey, was the exposure and depressurization of expansion joints. This circumstance led to chipping of the protective concrete layer of the floor slabs in the area of joints, corrosion of reinforcement and concrete due to leaks and ingress of aggressive moisture. In addition, inclined cracks were found on the facing in the columns consoles.

There were no identified defects in the skeleton columns, that would indicate significant decrease in their load-bearing capacity or overload of structures. Based on the results obtained in 2011-2012, MGSU developed a project for strengthening of parking No. 1 with metal structures, which was implemented.

The next survey of the parking No.2 structures was carried out by OOO "Tekhmet" in 2016. During the survey, the formation of new cracks in the slabs and floor beams was noted, and their technical condition was assessed as being limited in operation.

Limited in operation state of the parking No.1 and No.2 was also noted in the conclusions of the technical reports of OOO "RSP", obtained during visual inspection in 2016.

OOO "RSP" and OOO "Tekhmet", relying on their surveys, recommended to strengthen and repair load-bearing structures of buildings.

Starting from May 2018 to the present, MGSU conducts geotechnical monitoring of the parking No.1 and No.2, according to the approved program.

The program of geotechnical monitoring includes various monitoring methods that complement each other and allow for regular monitoring of the load-bearing structures state in observed buildings to ensure their durability, reliability and safe operation. According to the monitoring program, a combination of works is planned:

- Geodetic monitoring with documentation of vertical movements (subsidence);

- Object monitoring - visual and instrumental survey, that allows to assess current technical condition of the main load-bearing structures of buildings;

- Electric-contact dynamic probing, which includes dynamic probing and current logging. Such type of probing allows to study geological section in a spot of up to 10-11 
meters in depth and to determine physical and mechanical properties of soils;

- Seismic acoustic sounding of foundations, using reflections on longitudinal and transverse waves, to determine the depth of the foundation footing, foundation-soil contact state, state of the foundation material and to detect major defects and cracks in the body of the foundation.

On period from May 2018 to February 2019, during the execution of works, main damages were identified that prevents safe operation of the No.1 and No.2 parking. Such damage includes:

- Cracks in columns, due to corrosion of the reinforcement (Fig.3, 4);

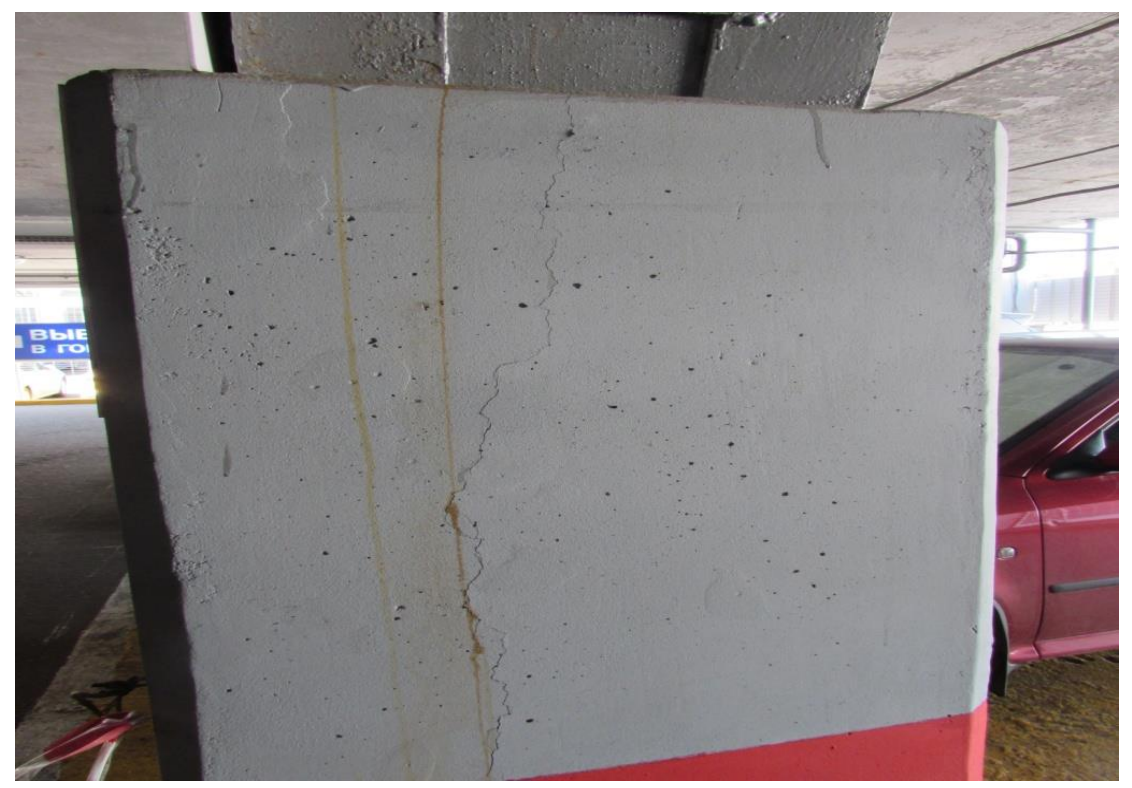

Fig. 3. Parking No.1, $1^{\text {st }}$ floor. Vertical column crack.

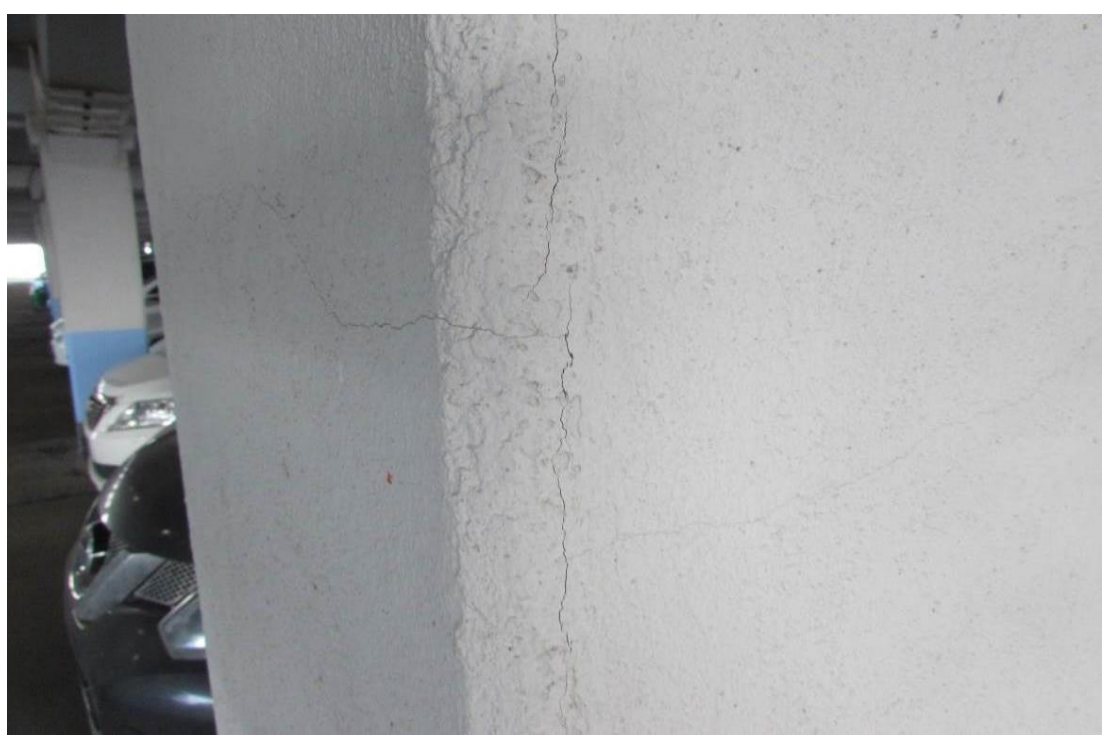

Fig. 4. Parking No.2, $1^{\text {st }}$ floor. Vertical column crack. 
- Extended cracks on the lower surface of the floor slabs, with an opening width of more than $0.3 \mathrm{~mm}$, with traces of rust and efflorescence (Fig.5, 6);

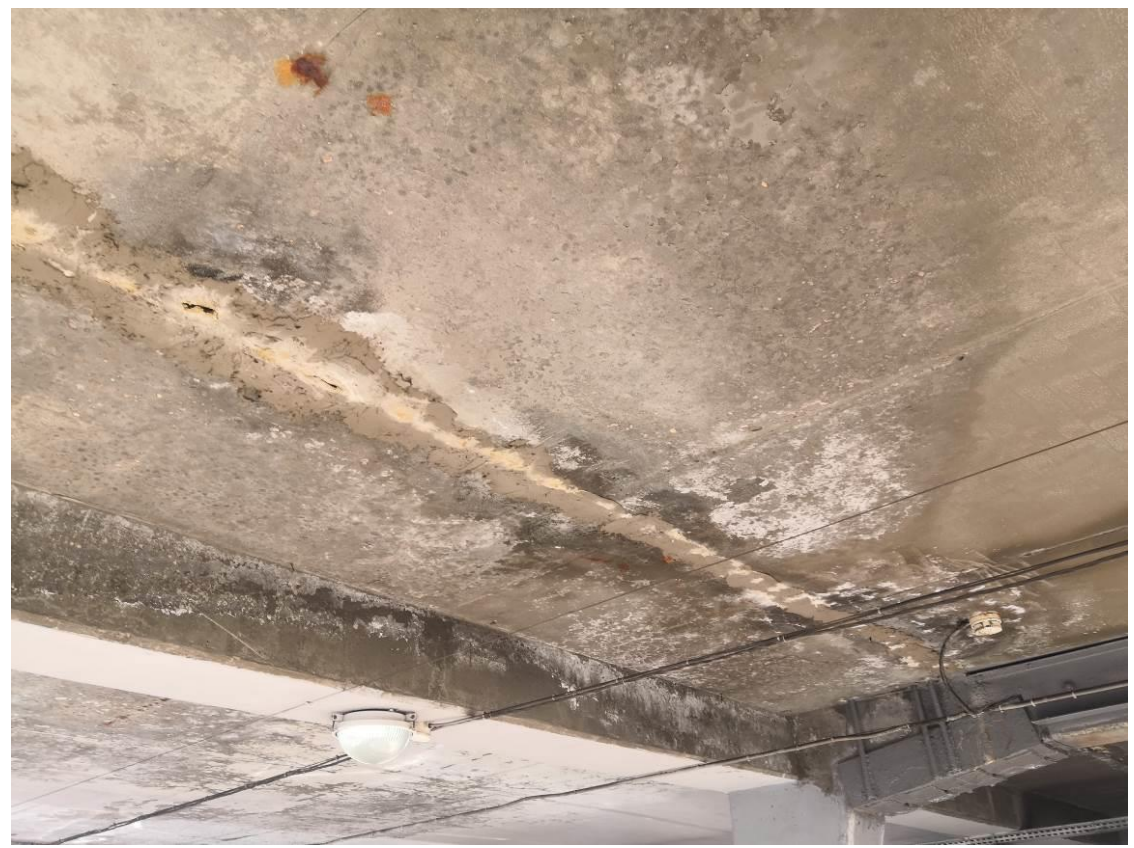

Fig. 5. Parking No.1, 3rd floor. Efflorescence on the slabs surface at the expansion joints

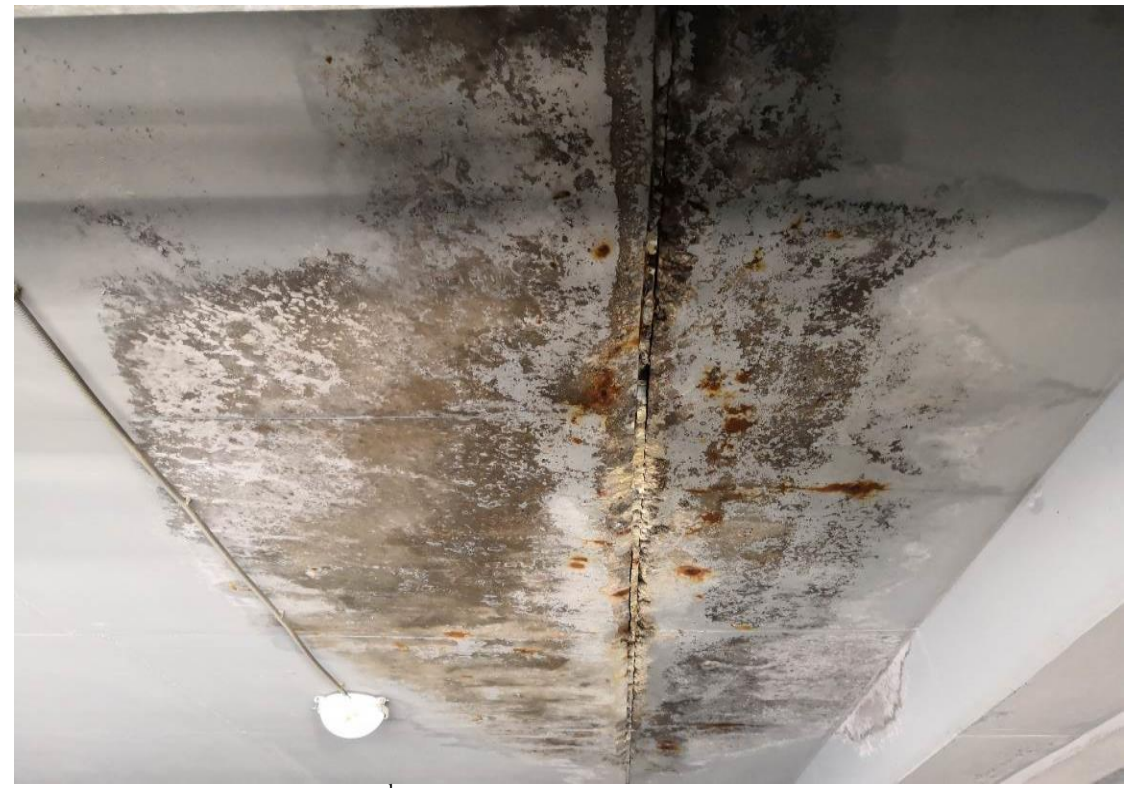

Fig. 6. Parking No.2, $2^{\text {nd }}$ floor. Cracks in the slab with traces of efflorescence and corrosion of reinforcement

- Deflection of floor slab sections between expansion joints (Fig.7, 8). 


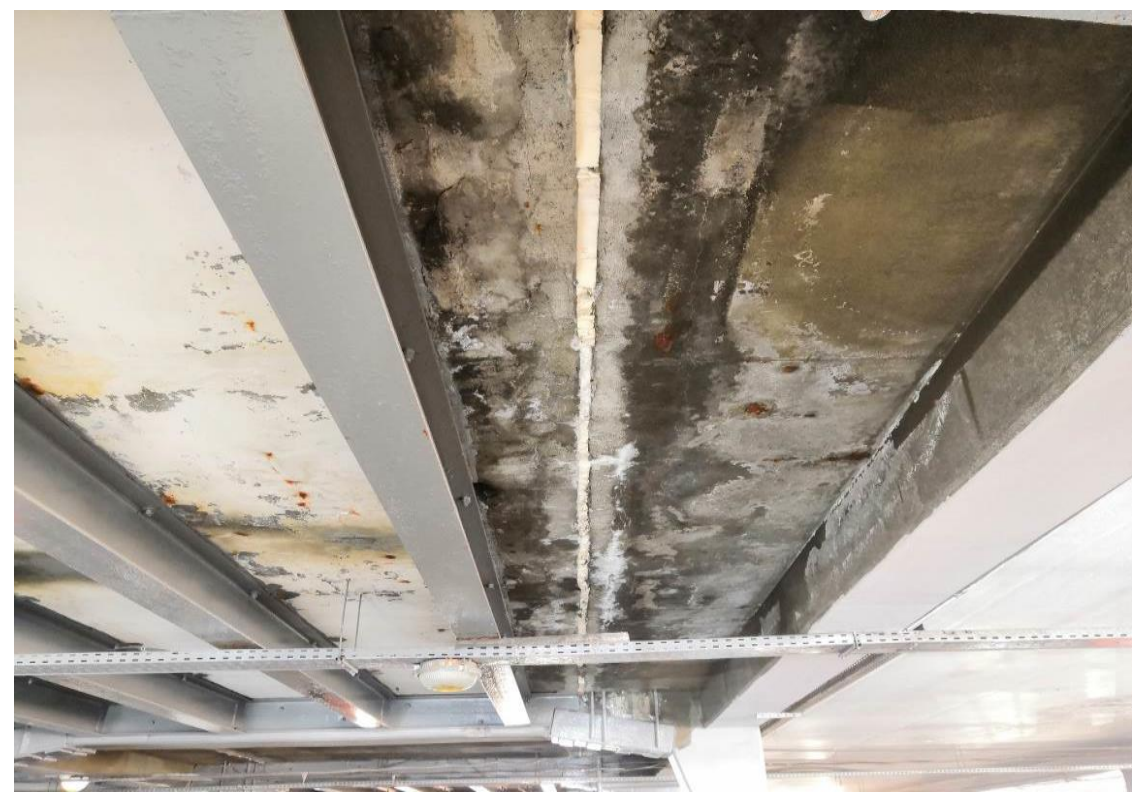

Fig. 7. Parking No.1. Deflections and efflorescence on the floor slab surface between the expansion joints

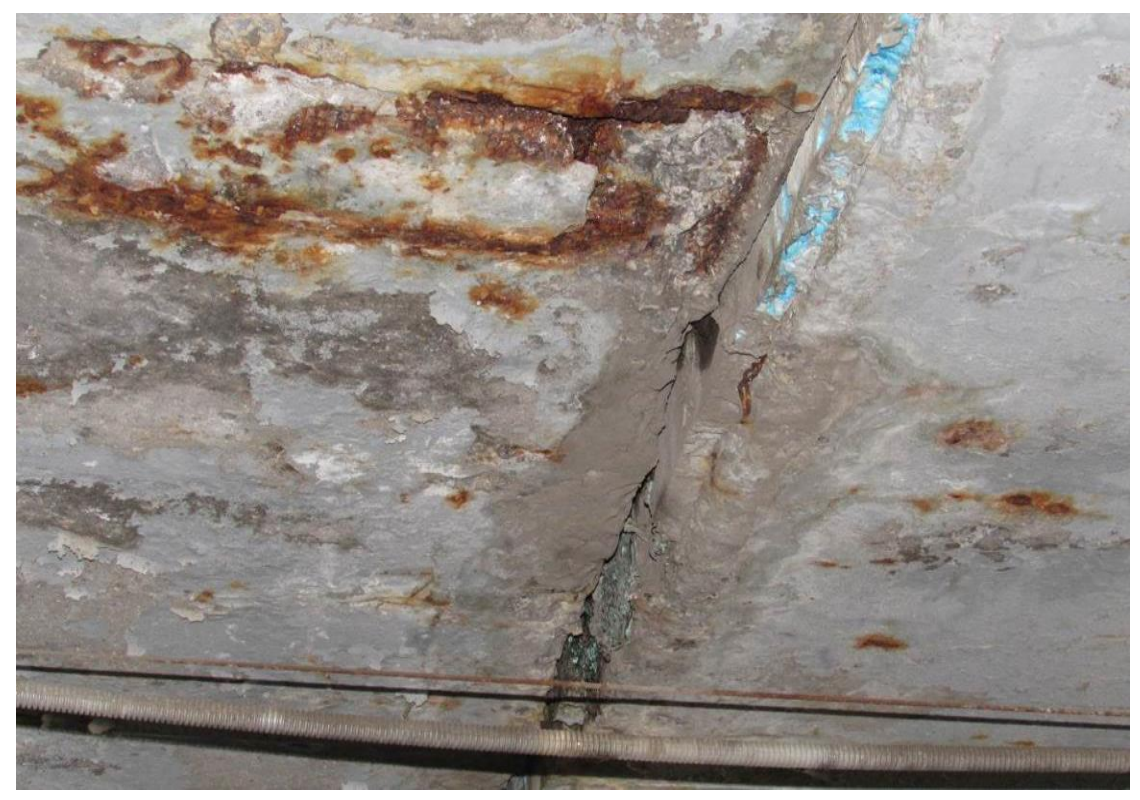

Fig. 8. Parking No.2. Deflections of floor slab sections between expansion joints. 1st floor

As mentioned above, Parking No.2 has undergone significant deformations from the construction of the railway tunnel and the new terminal complex. To date, according to geodetic monitoring, subsidence of Parking No.1 and No.2 buildings is within the limits of measurement accuracy and do not cause concern.

Conducting object monitoring and comparing the results obtained with data from previous studies showed an increased number of cracks in the parking structures. The 
dynamic of the crack number development over time in structures of both parking buildings for the period from 2005 to 2019 is shown in Fig.9.

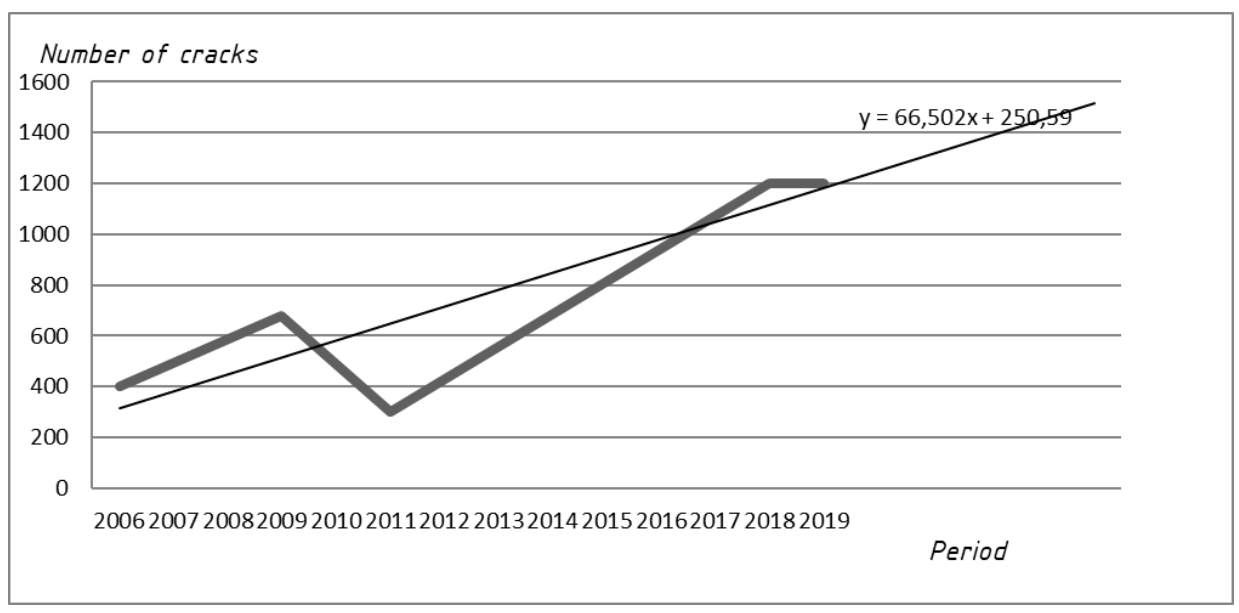

Fig. 9. Approximation of damage increment graph

From Fig.9 it follows that over time, there is a clearly pronounced tendency for defects growth in structures of the observed buildings. Moreover, main damage increment is observed in the winter-spring period of the year. According to the results of object monitoring, the state of parking No.1 is assessed as operational, and parking No.2 is assessed as limited in operation.

According to the data obtained over the course of monitoring, damageability of the structures was assessed according to the methodology [3] for assessing reliability of buildings and structures by external signs. Remaining operational life expectancy of parking No.1, i.e. projected period for repair works and strengthening of structures to extend service life is 2 years, at the same time remaining operational life expectancy for parking No.2 is absent. In this regard, parking No.2 requires full repair and strengthening of building structures.

Conducted geophysical research allowed to assess the soil under the foundation footing and the state of the foundation itself. Homogeneous geological section in the plan and shallow weak zones in section's upper part, directly under the footing of the foundation were discovered. Comparison of the obtained results with the data of surveys carried out by MGSU in 2005 showed that the physical mechanical characteristics of the soils up to the explored depth are almost coincide within the accuracy of the method.

According to the results of seismic acoustic sounding of the foundations, the depth of the examined foundations is within $2.85-3.05 \mathrm{~m}$, and the strength of the concrete foundations was determined by uniaxial compression.

The state of contact of the foundation with the soil is characterized as good and satisfactory. There was no unsatisfactory state of contact of the foundation with the ground. Major defects that violate the continuity of the parking buildings foundations body were not identified.

\section{Conclusions}

Analysis of the geotechnical monitoring results conducted over a period of 14 years leads to the following conclusions: 
- conducting geotechnical monitoring from the initial stage of construction allows to fix in time negative processes occurring in the structures of the building and in the soil base. And if necessary, to develop measures preventing a hazardous situation.

- Conducting comprehensive research as part of the geotechnical monitoring, combining geodetic, survey, geophysical and analytical methods that complement each other, makes it possible to carry out regular monitoring of the load-bearing structure state of observed buildings to ensure their strength and safe operation;

- Several years of geotechnical monitoring for buildings operation allows to ensure safety and reliability of their structures, which were adversely affected during construction period.

\section{References}

1. SNiP 2.02.01-83* Osnovaniya zdaniy i sooruzheniy (1985)

2. SP 13-102-2003 «Pravila obsledovaniya nesushchikh stroitel'nykh konstruktsiy zdaniy i sooruzheniy» (2003)

3. Rekomendatsii po otsenke nadezhnosti stroitel'nykh konstruktsiy zdaniy i sooruzheniy po vneshnim priznakam (2001) 